\title{
Vitamin D insufficiency/deficiency is associated with insulin resistance in Brazilian children, regardless of body fat distribution
}

\author{
Luana Cupertino Milagres ${ }^{1, *}$, Naruna Pereira Rocha ${ }^{1}$, Mariana de Santis Filgueiras ${ }^{1}$, \\ Fernanda Martins de Albuquerque ${ }^{\prime}$, Ana Paula Pereira Castro ${ }^{1}$, Milene Cristine Pessoa ${ }^{2}$, \\ Maria do Carmo Gouveia Peluzio ${ }^{1}$ and Juliana Farias de Novaes ${ }^{1}$ \\ 'Department of Nutrition and Health, Federal University of Viçosa, Biological Sciences Center, Viçosa, CEP \\ 36570-900, MG, Brazil: ${ }^{2}$ Department of Nutrition, Federal University of Minas Gerais, Belo Horizonte, MG, Brazil
}

Submitted 11 January 2017: Final revision received 24 May 2017: Accepted 26 June 2017: First published online 22 August 2017

\begin{abstract}
Objective: To assess the prevalence of vitamin D insufficiency and deficiency and its association with cardiometabolic risk factors, controlled by adiposity, in a representative sample of prepubescent children.

Design: Cross-sectional population-based study. Body composition was evaluated by dual-energy X-ray absorptiometry. Anthropometric measures and blood pressure were performed. Laboratory analyses were performed to determine the levels of vitamin D (25-hydroxyitamin D; 25(OH)D), glucose, insulin, serum lipids and intact parathyroid hormone. Dietary intake was assessed by three $24 \mathrm{~h}$ recalls. Setting: Viçosa, Minas Gerais, Brazil, 2015.

Subjects: Representative sample of 378 children aged 8 and 9 years from urban schools.

Results: Inadequate serum concentrations of $25(\mathrm{OH}) \mathrm{D}$ were diagnosed in more than half of the children and none of them met the recommended vitamin D intake. After adjusting for confounding factors in the multiple regression analysis, lower prevalence of insulin resistance and hypertriacylglycerolaemia was found in children with serum 25(OH)D levels $\geq 75 \mathrm{nmol} / 1$ (prevalence ratio $=0.25 ; 95 \%$ CI $0.08,0.85$ ) and $\geq 50 \mathrm{nmol} / 1$ (prevalence ratio $=0.61 ; 95 \%$ CI $0.37,0.99$ ), respectively. However, after adjusting for different indicators of adiposity, insulin resistance remained independently associated and the association with hypertriacylglycerolaemia was lost after adjusting for central adiposity. The prevalence of vitamin D insufficiency/deficiency was associated with the number of cardiometabolic alterations in children.

Conclusions: The study results showed that prevalence of vitamin D insufficiency/ deficiency was high among the children and insulin resistance was the main cardiometabolic alteration associated with this condition, even in a tropical climate country such as Brazil.
\end{abstract}

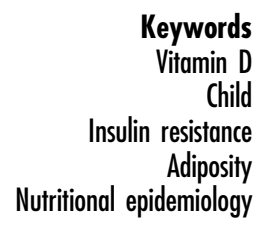

Hypovitaminosis D has become a global health problem and high prevalence of inadequate serum vitamin $\mathrm{D}$ has been reported even in tropical countries such as Brazil ${ }^{(1,2)}$. During childhood, an appropriate serum concentration of vitamin D (25-hydrovyvitamin D; 25(OH)D) is essential for bone health, since its deficiency can lead to rickets, growth retardation and muscle weakness ${ }^{(3)}$.

Vitamin D is a steroid hormone synthesized in the skin from exposure to sunlight, which is its main source, but it can also be obtained from food sources such as cod-liver oil and fatty fish (salmon, sardine, tuna). The risk factors for vitamin D deficiency are related to its decreased cutaneous synthesis caused by low sun exposure, high latitudes, colder seasons, older age and skin pigmentation ${ }^{(1,4)}$.
Recent behavioural, social and cultural changes favour sedentary behaviour, limiting physical activity - especially outdoor activities - and, as result, sun exposure, which are also important factors related to vitamin D insufficiency/ deficiency ${ }^{(5)}$. Furthermore, overweight and obese children generally spend less time outdoors because of a sedentary lifestyle ${ }^{(6)}$.

Vitamin D functions associated with Ca homeostasis and bone health are traditionally recognized, and only after its receptor was found in other tissues such as skin, placenta, brain, breast and pancreas did research begin on the additional effects of vitamin D not related to bone tissue ${ }^{(4)}$. Despite the physiological mechanisms not yet being fully understood, studies have shown the association of 
hypovitaminosis D with various chronic diseases, including insulin resistance, dyslipidaemia and hypertension, even in children $^{(7-9)}$. However, we found no reports of studies of this nature in developing countries.

Vitamin D deficiency is associated with several cardiometabolic risk factors that contribute to the development of type 2 diabetes mellitus and CVD, the main causes of morbidity and mortality in the developed world ${ }^{(10,11)}$. This association is influenced by body adiposity, since vitamin D is lipid-soluble and its serum concentration tends to be reduced in individuals with excess body fat ${ }^{(12)}$.

In addition, the inverse association between vitamin $\mathrm{D}$ and metabolic syndrome may be influenced by glucose homeostasis ${ }^{(13-15)}$. Studies with children and adolescents found an association between serum vitamin D and insulin sensitivity mediated by body fat, as well as that vitamin D supplementation improved insulin resistance and metabolic syndrome score in obese individuals ${ }^{(12,16)}$. Thus, vitamin D deficiency in the paediatric age group associated with obesity may lead to increased risk of changes in glucose metabolism. However, other studies have found controversial results ${ }^{(17,18)}$.

Excessive adiposity from infancy onwards increases the risk for metabolic disorders related to glucose homeostasis, control of blood pressure and lipid profile ${ }^{(19)}$. Obesity and body fat are also factors associated with lower serum concentrations of vitamin $\mathrm{D}^{(12)}$. Therefore, adjusting for a potential confounding effect of fat mass is important when assessing associations between concentrations of vitamin D and cardiometabolic risk factors. Most studies with children have used BMI, which does not cover information on body composition, and hence more accurate measures of body fat become important in epidemiological studies.

Identifying modifiable cardiovascular risk factors in childhood can help in long-term disease prevention. It is important to consider childhood as a strategic period for assessing serum levels of $25(\mathrm{OH}) \mathrm{D}$ and promotion of healthy habits. In Brazil, few studies have assessed the prevalence of vitamin D deficiency and insufficiency and its relationship with cardiometabolic disorders, particularly in children. Thus, the present study aimed to assess the prevalence of vitamin D insufficiency and deficiency and its association with cardiometabolic risk factors, controlled by adiposity, in a representative sample of prepubescent Brazilian children.

\section{Methods}

\section{Study design and participants}

Participants in the present study came from the Survey of Health Assessment of Schoolchildren (PASE), a crosssectional population-based study with 378 children aged 8 and 9 years from all public and private schools ( $n$ 24) in the urban area of the city of Viçosa, Minas Gerais, Brazil.
Viçosa is located in the Zona da Mata Region of Minas Gerais, $227 \mathrm{~km}$ from the state capital Belo Horizonte. It features a per capita Gross Domestic Product of R\$ 9597.00 (\$US 3024.00) and a Human Development Index of 0.775 , which is considered high, higher than the state $(0.731)$ and national $(0.755)$ indices ${ }^{(20)}$.

The PASE is a cross-sectional population-based study with children enrolled in urban schools to evaluate the cardiovascular health of these children in the city of Viçosa. In 2015, the city had twenty-four urban schools (seventeen public and seven private) that served children aged 8 and 9 years, totalling 1464 children enrolled. The sample size was calculated using the software Epi Open version 3.03 from the total number of children aged 8 and 9 years ( $n$ 1464) enrolled in all urban schools in 2015. Considering the analysis of multiple outcomes and the lack of studies on the prevalence of vitamin D insufficiency in children in south-eastern Brazil, the sample was calculated on the basis of $50 \%$ prevalence, $5 \%$ error tolerated, 95\% CI, $5 \%$ significance level and $20 \%$ estimated loss, resulting in the sample size of 366 children.

Currently, there is no consensus on cut-off points for the classification of $25(\mathrm{OH}) \mathrm{D}$ deficiency in clinical practice. However, vitamin D deficiency has been defined as below $50 \mathrm{nmol} / \mathrm{l}(20 \mathrm{ng} / \mathrm{ml})$ by many specialists, while sufficiency values range from 50 to $80 \mathrm{nmol} / 1$ (20 to $32 \mathrm{ng} / \mathrm{ml})^{(2,4,21)}$. In the current study, the concentration of vitamin $\mathrm{D}$ is expressed as $\mathrm{nmol} / \mathrm{l}(2.5 \mathrm{nmol} / \mathrm{l}=1 \mathrm{ng} / \mathrm{ml})$ and deficiency, insufficiency and sufficiency were defined when values were $<50, \geq 50-<75$ and $\geq 75 \mathrm{nmol} / 1$, respectively ${ }^{(4,21-23)}$.

The schoolchildren were selected by stratified random sampling. The sample from each school met the proportionality ratio of students enrolled by age and gender. The selection of children was done by random simple draw until the necessary number for each school was completed.

The child did not participate in the study if taking medication that interfered with the metabolism of vitamin D (corticosteroids, anticonvulsants and antifungals), glucose and/or lipids, as well as vitamin or mineral supplements. Data collection took place between May and November of 2015.

The study was conducted according to the guidelines established in the Declaration of Helsinki and all procedures involving human subjects were approved by the Ethics Committee on Human Research of the Federal University of Viçosa (opinion number 663171/2014) and also presented to the Municipal Department of Education, the Regional Superintendent of Education and principals of schools. Informed consent was signed by the parents.

\section{Anthropometry and body composition}

Weight and height were measured using an electronic digital scale (Tanita ${ }^{\circledR}$, model BC 553, Arlington Heights, IL, USA) and a portable stadiometer (Alturexata ${ }^{\circledR}$, Belo Horizonte, MG, Brazil), respectively. 
The nutritional status of children was assessed based on BMI, according to the BMI-for-age $Z$-scores proposed by the $\mathrm{WHO}^{(24)}$. Waist circumference was measured at the midpoint between the iliac crest and the last rib using a flexible and inelastic tape measure. Abdominal adiposity values above the 90th percentile according to age and gender were considered excessive, as proposed for Brazilian children ${ }^{(25)}$. Waist-to-height ratio was calculated by dividing waist (in centimetres) by height (in centimetres).

Total and regional body composition, android fat and gynoid fat were assessed by dual-energy X-ray absorptiometric scanning, in the morning, after an overnight fast, with children in a supine position. The total and regional body fat are reported as percentages and expressed as fat mass index (FMI), an index of fat mass-for-height $\left(\mathrm{kg} / \mathrm{m}^{2}\right)$. Excess body fat was classified according to the cut-off points proposed by Lohman ${ }^{(26)}$

\section{Biochemical and clinical assessment}

Blood samples were collected by venepuncture into serum gel tubes after $12 \mathrm{~h}$ of fasting for further analysis. Glucose, total cholesterol, HDL cholesterol, LDL cholesterol and TAG were determined by the enzymatic colorimetric method using the commercial kit Bioclin ${ }^{\circledR}$ (Belo Horizonte, MG, Brazil), following the manufacturer's instructions, and measured in an automatic biochemistry analyser (Mindray BS-200 ${ }^{\circledR}$, Nanshan, China).

Insulin, calcidiol $(25(\mathrm{OH}) \mathrm{D})$ and intact parathyroid hormone were determined by chemiluminescence immunoassay at the Clinical Analysis Laboratory of the Health Division, Federal University of Viçosa.

$25(\mathrm{OH}) \mathrm{D}$ was determined by the $\operatorname{Architect}^{\circledR} 25-\mathrm{OH}$ Vitamin D assay, which was developed to have correlation coefficient $\geq 0 \cdot 80$ for serum samples when compared with the LIAISON ${ }^{\circledR}$ DiaSorin $25-\mathrm{OH}$ Vitamin D Total assay. The Architect 25-OH Vitamin D assay has been developed to have an imprecision of $\leq 10 \%$ (within-laboratory total $\mathrm{CV}$ ).

Values were considered increased when fasting glucose was $\geq 100 \mathrm{mg} / \mathrm{dl}$ and fasting insulin was $\geq 15 \mathrm{mU} / \mathrm{ml}^{(27)}$. The homeostasis model assessment of insulin resistance (HOMA-IR) was calculated. There is no default setting for insulin resistance, particularly in children, but it has been shown that a HOMA-IR cut-off of about 3 could be used for this age group ${ }^{(28)}$. Therefore, we considered HOMA-IR $\geq 3 \cdot 16$ according to the I Atherosclerosis Prevention Guideline on Childhood and Adolescence of the Brazilian Society of Cardiology ${ }^{(27)}$.

The lipid profile was classified using specific cut-off points for children. Values were considered altered when total cholesterol was $\geq 3.9 \mathrm{mmol} / \mathrm{l}(150 \mathrm{mg} / \mathrm{dl})$, LDL cholesterol was $\geq 2.6 \mathrm{mmol} / 1 \quad(100 \mathrm{mg} / \mathrm{dl})$, TAG was $\geq 1.1 \mathrm{mmol} / \mathrm{l} \quad(100 \mathrm{mg} / \mathrm{dl})$ and HDL cholesterol was $<1.2 \mathrm{mmol} / \mathrm{l}(45 \mathrm{mg} / \mathrm{dl})^{(27)}$.

Blood pressure was measured with the child in sitting position after resting for at least $5 \mathrm{~min}$ at three different times. The mean values were used to classify children. Systolic or diastolic pressure was considered altered when greater than the 90th percentile, proposed by the VI Brazilian guidelines of hypertension by the Brazilian Society of Cardiology, according to age, gender and height percentile $^{(29)}$. Measurements were carried out using an automatic inflation blood pressure monitor $\left(\mathrm{OMRON}^{\circledR}\right.$ HEM 907, Vernon Hills, IL, USA).

\section{Dietary assessment}

Dietary intake was assessed by three $24 \mathrm{~h}$ recalls, on nonconsecutive days, including one weekend day. The interval between the recalls was 15 to $20 \mathrm{~d}$. The children responded to the dietary survey accompanied by their parents or guardians who were also interviewed, preferably the one directly involved with the child's diet.

The quantities of foods consumed in the portion sizes were converted to grams or millilitres for further chemical composition analysis. The analysis of dietary data was performed using the Diet Pro ${ }^{\circledR} 5 \mathrm{i}$ software, version 5.8.

Vitamin D intake was compared with the Estimated Average Requirement, proposed by the US Institute of Medicine, of $10 \mu \mathrm{g} / \mathrm{d}(400 \mathrm{IU} / \mathrm{d})^{(30)}$. Adjustment for the effect of energy consumption on macro- and micronutrients was carried out using the residual method proposed by Willett and Stampfer ${ }^{(31)}$.

\section{Questionnaire}

Information on demographic and socio-economic characteristics was collected by personal interview with the child and parents. Per capita income was obtained by dividing the total income of the family by the number of dependants. Maternal education was measured by the number of years of schooling completed by the mother.

The parents/guardians declared the child's ethnicity and the skin colour was categorized as white, brown or black. The season of the year was evaluated during the time of blood collection.

Based on the child's life habits, sedentary behaviour was defined as activities that do not increase energy expenditure substantially above rest, such as watching television or engaging in other forms of screen-based entertainment ${ }^{(32)}$. Sedentary behaviour was classified as screen time $\geq 2 \mathrm{~h} / \mathrm{d}^{(33)}$. The time of sun exposure was defined according to the outdoor activities that the children performed.

\section{Statistical analyses}

Statistical analyses were performed with the statistical software packages IBM SPSS Ststistics version 20.0 and Stata version 13.1. Normality was assessed by the Kolmogorov-Smirnov test. Mean and SD are presented for variables with normal distribution, and median and interquartile range for variables without normal distribution. Pearson's $\chi^{2}$ test, Fisher's exact test and the $\chi^{2}$ linear trend test were used to analyse the relationship between 
categorical variables. Differences in quantitative variables between two groups were assessed by Student's $t$ test or the Mann-Whitney $U$ test.

Poisson regression with robust variance was performed to estimate the association of cardiometabolic risk factors with deficiency and insufficiency of vitamin $\mathrm{D}$. The prevalence ratio (PR) with $95 \%$ CI was used as a measure of effect. The analyses were conducted having the cardiometabolic changes as the dependent variable. Multivariate models were adjusted for age, gender, season, ethnic group, parathyroid hormone, per capita income, maternal schooling, vitamin D intake, sedentary behaviour and percentage of body fat. Additional adjustment for different measures of adiposity as a potential confounding factor was also done, replacing the percentage of body fat in those models that had initially shown significant associations. The goodness-of-fit test was used to evaluate the adjustment of the final model. We considered the group with the lowest concentration of vitamin D as reference.

Finally, the association between the prevalence of insufficiency and deficiency of vitamin D and the number of cardiometabolic alterations (excessive body and abdominal adiposity, hypercholesterolaemia, hypertriacylglycerolaemia, high LDL cholesterol, low HDL cholesterol, hypertension, insulin resistance) was assessed using simple linear regression analysis. The prevalence of vitamin D insufficiency/deficiency was considered as dependent variable, while cardiometabolic alterations were considered as independent variables.

The significance level of 0.05 ( $\alpha=5 \%$ ) was adopted for all tests.

\section{Results}

About half of the children were 9 years old (51.6\%) and female $(52 \cdot 1 \%)$. Regarding skin colour, $55 \cdot 8 \%$ were brown, $32.8 \%$ white and $11.4 \%$ black. The prevalence of deficiency and insufficiency of vitamin D was 12.2 and $43.4 \%$, respectively (prevalence of sufficiency was $55 \cdot 6 \%$ ). No child had 25(OH)D below $25 \mathrm{nmol} / \mathrm{l}$.

Sedentary behaviour was more prevalent in boys $(P=0.026)$. The mean vitamin D intake $(1.68 \mu \mathrm{g} / \mathrm{d})$ was $83.2 \%$ lower than the Estimated Average Requirement, and it is noteworthy that no child reached the Estimated Average Requirement. Girls had higher mean body adiposity while boys had higher mean HDL cholesterol $(P<0.05)$. There was no difference in the nutritional status of 25(OH)D and anthropometric measurements between genders (Table 1). We also found no difference in the time of sun exposure in relation to sedentary behaviour $(P=0 \cdot 134)$; however, a longer sun exposure was observed in the autumn $(P<0 \cdot 001)$.

The mean values of anthropometric measurements, body composition, biochemical variables and blood

Table 1 Characteristics of the study population of Brazilian children ( $n$ 378) aged 8-9 years, Viçosa, Minas Gerais, Brazil, 2015

\begin{tabular}{|c|c|c|c|c|c|c|c|}
\hline & \multicolumn{2}{|c|}{ Total (n 378) } & \multicolumn{2}{|c|}{ Boys ( $n$ 181) } & \multicolumn{2}{|c|}{ Girls (n 197) } & \multirow[b]{2}{*}{$P$} \\
\hline & $\begin{array}{c}n, \text { median or } \\
\text { mean }\end{array}$ & $\%$, IQR or SD & $\begin{array}{c}n, \text { median or } \\
\text { mean }\end{array}$ & $\%$, IQR or SD & $\begin{array}{c}n, \text { median or } \\
\text { mean }\end{array}$ & $\%$, IQR or SD & \\
\hline \multicolumn{8}{|l|}{$25(\mathrm{OH}) \mathrm{D} \dagger, n$ and $\%$} \\
\hline Sufficiency $(\geq 75 \mathrm{nmol} / \mathrm{l})$ & 167 & 44.40 & 88 & $52 \cdot 70$ & 79 & $47 \cdot 30$ & 0.357 \\
\hline Insufficiency $(\geq 50-<75 \mathrm{nmol} / \mathrm{l})$ & 163 & $43 \cdot 40$ & 68 & $41 \cdot 70$ & 95 & $58 \cdot 30$ & \\
\hline Deficiency $(<50 \mathrm{nmol} / \mathrm{l})$ & 46 & $12 \cdot 20$ & 24 & $52 \cdot 20$ & 22 & $47 \cdot 80$ & \\
\hline \multicolumn{8}{|l|}{ Sedentary behaviour, $n$ and $\%$} \\
\hline$\leq 2 \mathrm{~h} / \mathrm{d}$ & 198 & $52 \cdot 40$ & 84 & $42 \cdot 40$ & 114 & $57 \cdot 60$ & $0.026^{\star}$ \\
\hline$>2 \mathrm{~h} / \mathrm{d}$ & 180 & $47 \cdot 60$ & 97 & 53.90 & 83 & $46 \cdot 10$ & \\
\hline Per capita income $(\mathrm{R} \$)$, median and IQR & $500 \cdot 00$ & $312 \cdot 00-844 \cdot 25$ & $500 \cdot 00$ & $294 \cdot 17-817 \cdot 00$ & $500 \cdot 00$ & $326.00-923.00$ & 0.762 \\
\hline $\begin{array}{l}\text { Maternal education (years), median and } \\
\text { IQR }\end{array}$ & $11 \cdot 00$ & $7 \cdot 00-11.00$ & 11.00 & $7 \cdot 00-11 \cdot 00$ & 11.00 & $8.00-11.00$ & 0.608 \\
\hline Vitamin D intake $(\mu \mathrm{g} / \mathrm{d})$, mean and SD & 1.68 & $1 \cdot 25$ & $1 \cdot 84$ & $1 \cdot 25$ & 1.53 & 1.23 & 0.097 \\
\hline HOMA-IR, median and IQR & 0.95 & $0.65-1.46$ & 0.90 & $0.60-1.80$ & 1.00 & $0.68-2 \cdot 32$ & 0.067 \\
\hline SBP $(\mathrm{mmHg})$, mean and SD & $102 \cdot 92$ & $8 \cdot 73$ & $103 \cdot 24$ & $8 \cdot 18$ & $102 \cdot 62$ & $9 \cdot 23$ & 0.487 \\
\hline DBP $(\mathrm{mmHg})$, mean and sD & 60.82 & $6 \cdot 78$ & 60.33 & $6 \cdot 34$ & $61 \cdot 27$ & $7 \cdot 15$ & 0.181 \\
\hline $\mathrm{TC}(\mathrm{mmol} / \mathrm{l})$, mean and SD & 3.94 & 0.68 & 3.93 & 0.66 & 3.94 & 0.71 & 0.891 \\
\hline HDL-C (mmol/l), median and IQR & $1 \cdot 27$ & $1.11-1.45$ & 1.29 & $1.14-1.50$ & 1.24 & $1.09-1.40$ & $0.015^{\star}$ \\
\hline LDL-C (mmol/l/), mean and SD & $2 \cdot 25$ & 0.60 & $2 \cdot 21$ & 0.57 & $2 \cdot 29$ & 0.64 & 0.193 \\
\hline TAG (mmol/l), median and IQR & 0.82 & $0.63-1.02$ & 0.78 & $0.59-0.99$ & 0.85 & $0.64-1.07$ & 0.075 \\
\hline BMI Z-score, mean and SD & 0.41 & 1.40 & 0.44 & 1.49 & 0.38 & 1.33 & 0.693 \\
\hline WC $(\mathrm{cm})$, median and IQR & 57.60 & $53 \cdot 50-65.60$ & 58.00 & $54.80-64.75$ & $57 \cdot 00$ & $52 \cdot 90-66 \cdot 70$ & 0.218 \\
\hline WHtR, median and IQR & 0.43 & $0.41-0.47$ & 0.43 & $0.41-0.47$ & 0.43 & $0.40-0.48$ & 0.641 \\
\hline BF (\%), median and IQR & $22 \cdot 75$ & $16 \cdot 0-32 \cdot 13$ & $19 \cdot 00$ & $13 \cdot 10-30 \cdot 00$ & $25 \cdot 40$ & $19 \cdot 15-34 \cdot 90$ & $<0.001^{\star}$ \\
\hline FMI $\left(\mathrm{kg} / \mathrm{m}^{2}\right)$, median and IQR & 3.65 & $2 \cdot 38-6 \cdot 15$ & $3 \cdot 11$ & $1.95-5.52$ & $4 \cdot 19$ & $2.95-6.73$ & $<0.001^{\star}$ \\
\hline AF $(\%)$, median and IQR & 14.85 & $7 \cdot 10-26 \cdot 18$ & $9 \cdot 50$ & $6 \cdot 00-22 \cdot 50$ & $17 \cdot 20$ & $8.65-28.05$ & $<0.001^{\star}$ \\
\hline GF $(\%)$, mean and SD & 31.37 & 11.47 & $27 \cdot 67$ & 11.68 & 34.76 & $10 \cdot 18$ & $<0.001^{\star}$ \\
\hline
\end{tabular}

IQR, interquartile range; 25(OH)D, 25-hydroxyvitamin D; HOMA-IR, homeostasis model assessment of insulin resistance; SBP, systolic blood pressure; DBP, diastolic blood pressure; TC, total cholesterol; HDL-C, HDL cholesterol; LDL-C, LDL cholesterol; WC, waist circumference; WHtR, waist-to-height ratio; BF, body fat; FMI, fat mass index; AF, android fat mass; GF, gynoid fat mass.

Variables with normal distribution (mean and SD) were evaluated by Student's $t$ test and variables without normal distribution (median and IQR) were evaluated by the Mann-Whitney $U$ test.

${ }^{*} P<0.05$.

$+x^{2}$ linear trend test. 
Table 2 Characteristics in relation to vitamin D status (sufficiency, insufficiency/deficiency) of the study population of Brazilian children ( $n$ 378) aged 8-9 years, Viçosa, Minas Gerais, Brazil, 2015

\begin{tabular}{|c|c|c|c|c|c|}
\hline & \multicolumn{2}{|c|}{$25(\mathrm{OH}) \mathrm{D} \geq 75 \mathrm{nmol} / \mathrm{l}(n$ 167) } & \multicolumn{2}{|c|}{$25(\mathrm{OH}) \mathrm{D}<75 \mathrm{nmol} / \mathrm{l}(n$ 209) } & \multirow[b]{2}{*}{$P$} \\
\hline & $n$, median or mean & $\%$, IQR or SD & $n$, median or mean & $\%$, IQR or SD & \\
\hline \multicolumn{6}{|l|}{ Ethnic groupt, $n$ and $\%$} \\
\hline White & 62 & $50 \cdot 00$ & 62 & $50 \cdot 00$ & $0.044^{*}$ \\
\hline Brown & 92 & 43.60 & 119 & $56 \cdot 40$ & \\
\hline Black & 13 & $31 \cdot 70$ & 28 & $68 \cdot 30$ & \\
\hline \multicolumn{6}{|l|}{ Seasont, $n$ and \% } \\
\hline Autumn & 41 & $59 \cdot 40$ & 28 & $40 \cdot 60$ & 0.345 \\
\hline Winter & 76 & $37 \cdot 30$ & 128 & $62 \cdot 70$ & \\
\hline Spring & 50 & $48 \cdot 50$ & 53 & 51.50 & \\
\hline \multicolumn{6}{|l|}{ Sedentary behaviour, $n$ and $\%$} \\
\hline$\leq 2 \mathrm{~h} / \mathrm{d}$ & 93 & $47 \cdot 4$ & 103 & $52 \cdot 6$ & 0.217 \\
\hline$>2 \mathrm{~h} / \mathrm{d}$ & 74 & $41 \cdot 1$ & 106 & $58 \cdot 9$ & \\
\hline Per capita income $(\mathrm{R} \$)$, median and IQR & 475.00 & $312 \cdot 00-946 \cdot 00$ & $500 \cdot 00$ & $312 \cdot 00-800 \cdot 00$ & 0.994 \\
\hline Maternal education (years), median and IQR & 11.00 & $7 \cdot 00-11.00$ & $11 \cdot 00$ & $7 \cdot 00-11.00$ & 0.578 \\
\hline Vitamin D $(\mu \mathrm{g} / \mathrm{d})$, mean and SD & 1.77 & $1 \cdot 34$ & 1.61 & $1 \cdot 13$ & $0 \cdot 160$ \\
\hline HOMA-IR $(\geq 3 \cdot 16) \ddagger, n$ and $\%$ & 1 & $11 \cdot 10$ & 8 & $88 \cdot 90$ & $0.047^{*}$ \\
\hline BP ( $\geq 90$ th percentile), $n$ and $\%$ & 12 & 48.00 & 13 & $52 \cdot 00$ & 0.718 \\
\hline TC $(\geq 3.9 \mathrm{mmol} / \mathrm{l}), n$ and $\%$ & 81 & $42 \cdot 20$ & 111 & $57 \cdot 80$ & 0.380 \\
\hline $\mathrm{HDL}-\mathrm{C}(<1.2 \mathrm{mmol} / \mathrm{l}), n$ and $\%$ & 49 & $44 \cdot 10$ & 62 & 55.90 & 0.951 \\
\hline LDL-C $(\geq 2.6 \mathrm{mmol} / \mathrm{l}), n$ and $\%$ & 44 & $42 \cdot 70$ & 59 & $57 \cdot 30$ & 0.689 \\
\hline TAG ( $\geq 1.1 \mathrm{mmol} / \mathrm{l}), n$ and $\%$ & 23 & $34 \cdot 80$ & 43 & $65 \cdot 20$ & 0.086 \\
\hline BMI (Z-score), mean and SD & 0.19 & $1 \cdot 31$ & 0.60 & 1.44 & $0.005^{\star}$ \\
\hline WC $(\mathrm{cm})$, median and IQR & $57 \cdot 00$ & $53 \cdot 10-62 \cdot 50$ & $59 \cdot 00$ & $54.00-69 \cdot 00$ & $0.003^{*}$ \\
\hline WHtR, median and IQR & 0.42 & $0.40-0.46$ & 0.43 & $0.41-0.49$ & $0.046^{*}$ \\
\hline BF (\%), median and IQR & 21.00 & $14 \cdot 10-30 \cdot 00$ & $24 \cdot 70$ & $17 \cdot 90-35 \cdot 40$ & $<0.001^{*}$ \\
\hline FMI $\left(\mathrm{kg} / \mathrm{m}^{2}\right)$, median and IQR & 3.33 & $2 \cdot 19-5 \cdot 32$ & $4 \cdot 14$ & $2.74-7.04$ & $<0.001^{*}$ \\
\hline $\mathrm{AF}(\%)$, median and IQR & 11.40 & $6 \cdot 30-22 \cdot 10$ & $17 \cdot 00$ & $8 \cdot 15-28 \cdot 75$ & $0.001^{*}$ \\
\hline GF (\%), mean and SD & 29.01 & $11 \cdot 11$ & $33 \cdot 38$ & $11 \cdot 31$ & $<0.001^{\star}$ \\
\hline
\end{tabular}

25(OH)D, 25-hydroxyvitamin D; IQR, interquartile range; HOMA-IR, homeostasis model assessment of insulin resistance; BP, blood pressure; TC, total cholesterol; HDL-C, HDL cholesterol; LDL-C, LDL cholesterol; WC, waist circumference; WHtR, waist-to-height ratio; BF, body fat; FMI, fat mass index; $\mathrm{AF}$, android fat mass; GF, gynoid fat mass.

Variables with normal distribution (mean and SD) were evaluated by Student's $t$ test and variables without normal distribution (median and IQR) were evaluated by the Mann-Whitney $U$ test.

${ }^{\star} P<0.05$.

$+x^{2}$ linear trend test.

†Fisher's exact test.

pressure did not differ by vitamin $\mathrm{D}$ intake tertile, and no association was found between serum concentrations and vitamin D intake. It is also noteworthy that the insufficiency/deficiency of $25(\mathrm{OH}) \mathrm{D}$ was compared between children from public and private schools and no statistical difference was found (data not presented).

The prevalence of insufficiency/deficiency of vitamin D $(<75 \mathrm{nmol} / \mathrm{l})$ was higher in black children $(68.3 \%)$ than in brown (56.4\%) and white $(50.0 \%)$ children. The prevalence of insulin resistance and the average values of anthropometric measurements and body composition were higher in children with insufficiency/deficiency of vitamin D (Table 2). After adjustment for confounding factors, in multiple regression analysis, the results showed that the prevalence of insulin resistance was lower in children with sufficient serum vitamin $\mathrm{D}$ concentration $(\mathrm{PR}=0.11 ; 95 \% \mathrm{CI} \quad 0.03,0.45)$ and this association remained significant after adjustment for the percentage of body fat ( $\mathrm{PR}=0.25 ; 95 \% \mathrm{CI} 0.08,0.85)$. The prevalence of hypertriacylglycerolaemia was lower in children with concentration of vitamin D $\geq 50 \mathrm{nmol} / \mathrm{l}(\mathrm{PR}=0.49 ; 95 \% \mathrm{CI}$ $0 \cdot 30,0 \cdot 81)$ than in deficient children and this association also remained after adjustment for body fat $(\mathrm{PR}=0.61$; 95\% CI 0.37, 0.99; Table 3). However, after additional adjustment for other indicators of body adiposity in multiple regression analysis, only insulin resistance remained independently associated. The association with TAG was lost after adjustment for central adiposity (Table 4).

High prevalence of cardiometabolic risk factors was observed in the children, including overweight (32.8\%), excessive body (49.7\%) and abdominal adiposity (29.6\%), insulin resistance (2.4\%), hypercholesterolaemia (23.4\%), low HDL cholesterol (29.8\%), high LDL cholesterol (4.0\%), hypertriacylglycerolaemia (7.7\%) and hypertension (4.8\%). The prevalence of insufficiency/deficiency of vitamin D was associated with the number of cardiometabolic alterations in children $(\beta=5.62 ; 95 \%$ CI 0.92, 10.32; $P=0.036$; Fig. 1$)$.

\section{Discussion}

The present study found a high prevalence of vitamin D insufficiency/deficiency among the children and insulin resistance was the main cardiometabolic alteration associated with this condition, regardless of body fat location. Although restricted to one city, the present study is the first, to our knowledge, which relates the nutritional status of vitamin $\mathrm{D}$ to cardiometabolic risk factors in a population-based sample of Brazilian children. 
Table 3 Poisson regression models estimating the association between cardiometabolic alterations and insufficiency/deficiency of vitamin $D$ in Brazilian children ( $n$ 378) aged 8-9 years, Viçosa, Minas Gerais, Brazil, 2015

\begin{tabular}{|c|c|c|c|c|c|c|c|c|c|c|c|c|}
\hline & \multicolumn{3}{|c|}{$25(\mathrm{OH}) \mathrm{D} \geq 50 \mathrm{nmol} / \mathrm{l}$} & \multicolumn{3}{|c|}{$25(\mathrm{OH}) \mathrm{D} \geq 50 \mathrm{nmol} / \mathrm{l}+\% \mathrm{BF} \dagger$} & \multicolumn{3}{|c|}{$25(\mathrm{OH}) \mathrm{D} \geq 75 \mathrm{nmol} / \mathrm{l}$} & \multicolumn{3}{|c|}{$25(\mathrm{OH}) \mathrm{D} \geq 75 \mathrm{nmol} / \mathrm{l}+\% \mathrm{BF} \dagger$} \\
\hline & PR & $95 \% \mathrm{Cl}$ & $P$ & PR & $95 \% \mathrm{Cl}$ & $P$ & PR & $95 \% \mathrm{Cl}$ & $P$ & PR & $95 \% \mathrm{Cl}$ & $P$ \\
\hline HOMA-IR $(\geq 3.16)$ & 0.63 & $0.12,3.47$ & 0.600 & 0.95 & $0.21,4.35$ & 0.951 & 0.11 & $0.03,0.45$ & $0.002^{*}$ & 0.25 & $0.08,0.85$ & $0.026^{*}$ \\
\hline BP ( $\geq 90$ th percentile) & 0.78 & $0.27,2 \cdot 21$ & 0.637 & 1.09 & $0.41,2.88$ & 0.865 & 1.21 & $0.55,2.67$ & 0.637 & $1 \cdot 79$ & $0.93,3.43$ & 0.082 \\
\hline $\mathrm{TC}(\geq 3.9 \mathrm{mmol} / \mathrm{l})$ & 0.83 & $0.64,1.09$ & 0.175 & 0.86 & $0.66,1.12$ & 0.260 & 0.91 & $0.74,1.12$ & 0.368 & 0.93 & $0.76,1.16$ & 0.530 \\
\hline HDL-C $(<1.2 \mathrm{mmol} / \mathrm{l})$ & 0.81 & $0.53,1.23$ & 0.321 & 0.84 & $0.55,1.28$ & 0.406 & 1.06 & $0.76,1.48$ & 0.717 & $1 \cdot 11$ & $0.79,1.55$ & 0.544 \\
\hline LDL-C $(\geq 2.6 \mathrm{mmol} / \mathrm{l})$ & 0.98 & $0.60,1.62$ & 0.944 & 1.07 & $0.63,1.81$ & 0.806 & 0.96 & $0.69,1.35$ & 0.834 & 1.04 & $0.74,1.47$ & 0.817 \\
\hline TAG $(\geq 1.1 \mathrm{mmol} / \mathrm{l})$ & 0.49 & $0.30,0.81$ & $0.005^{\star}$ & 0.61 & $0.37,0.99$ & $0.047^{\star}$ & 0.71 & $0.43,1.16$ & 0.171 & 0.83 & $0.51,1.36$ & 0.466 \\
\hline
\end{tabular}

25(OH)D, 25-hydroxyvitamin D; \%BF, body fat percentage; PR, prevalence ratio; HOMA-IR, homeostasis model assessment of insulin resistance; BP, blood pressure; TC, total cholesterol; HDL-C, HDL cholesterol; LDL-C, LDL cholesterol.

PR are presented for higher concentration of vitamin $D(\geq 50$ or $\geq 75 \mathrm{nmol} / \mathrm{l})$ and the group with lower concentration of vitamin $D$ was used as reference. All models were adjusted for age, sex, season, ethnic group, parathyroid hormone, per capita income, maternal education, vitamin D intake and sedentary behaviour.

${ }^{*} P<0.05$.

tInclusion of \%BF as an adjustment in the regression model.

Table 4 Poisson regression models estimating the association of deficiency/insufficiency of vitamin $D$ with insulin resistance and hypertriacylglycerolaemia, according to different body measurements, in Brazilian children ( $n$ 378) aged 8-9 years, Viçosa, Minas Gerais, Brazil, 2015

\begin{tabular}{lccc}
\hline & PR & $95 \% \mathrm{Cl}$ & $P$ \\
\hline 25(OH)D $\geq 75 \mathrm{nmol} / \mathrm{I}$ & & HOMA-IR \\
Adjusted for FMI $\left(\mathrm{kg} / \mathrm{m}^{2}\right)$ & 0.27 & $0.09,0.83$ & $0.023^{*}$ \\
Adjusted for AF $\%$ ) & 0.24 & $0.08,0.74$ & $0.013^{*}$ \\
Adjusted for GF (\%) & 0.21 & $0.05,0.80$ & $0.023^{*}$ \\
Adjusted for BMI Z-score & 0.24 & $0.07,0.86$ & $0.028^{*}$ \\
Adjusted for WHtR & 0.20 & $0.07,0.54$ & $0.002^{*}$ \\
25(OH)D $\geq 50 \mathrm{nmol} / \mathrm{I}$ & \multicolumn{3}{c}{ TAG } \\
Adjusted for FMI (kg/m²) & 0.64 & $0.39,1.06$ & 0.081 \\
Adjusted for AF (\%) & 0.63 & $0.38,1.05$ & 0.063 \\
Adjusted for GF (\%) & 0.58 & $0.35,0.94$ & $0.028^{*}$ \\
Adjusted for BMI Z-score & 0.59 & $0.37,0.96$ & $0.034^{*}$ \\
Adjusted for WHtR & 0.68 & $0.40,1.15$ & 0.152 \\
\hline
\end{tabular}

PR, prevalence ratio; 25(OH)D, 25-hydroxyvitamin D; FMI, fat mass index; $\mathrm{AF}$, android fat mass; GF, gynoid fat mass; WHtR, waist-to-height ratio; HOMA-IR, homeostasis model assessment of insulin resistance.

PR are presented for higher concentration of vitamin $D(\geq 50$ or $\geq 75 \mathrm{nmol} / \mathrm{l})$ and the group with lower concentration of vitamin $D$ was used as reference. All models were adjusted for age, sex, season, ethnic group, parathyroid hormone, per capita income, maternal education, vitamin D intake and sedentary behaviour

${ }^{\star} P<0.05$.

The prevalence of hypertriacylglycerolaemia and insulin resistance was lower in children with higher serum concentrations of vitamin D. The associations were independent of potential confounding factors and effects of adiposity on HOMA-IR but not on TAG. Central adiposity, but no other measures of adiposity, removed the explanatory power of vitamin D deficiency related to hypertriacylglycerolaemia.

The city of our study is located in the south-east of the country. In Brazil, higher prevalence of hypovitaminosis D was found in the south of the country, with $90.6 \%$ of inadequacy and $63.7 \%$ of deficiency in children and teenagers $^{(34)}$, and lower prevalence in the north of the country, with $32.0 \%$ of inadequacy among children ${ }^{(35)}$. In developed countries, studies have shown that prevalence reaches $93 \%$ of insufficiency in American children ${ }^{(36)}$, $51.6 \%$ of insufficiency in French children ${ }^{(37)}$ and $28.4 \%$ of

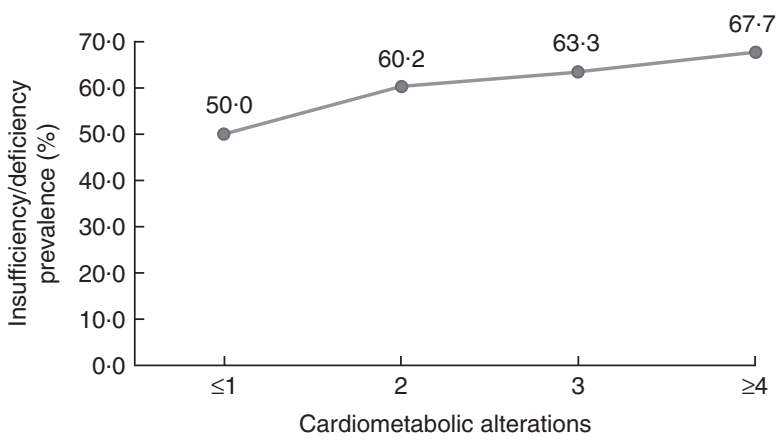

Fig. 1 Prevalence of insufficiency/deficiency of vitamin D (serum 25-hydroxyvitamin $\mathrm{D}<75 \mathrm{nmol} / \mathrm{l}$ ) according to the number of cardiometabolic alterations in Brazilian children (n 378) aged 8-9 years, Viçosa, Minas Gerais, Brazil, 2015 $(\beta=5.62 ; 95 \% \mathrm{Cl} 0.92,10.32 ; P=0.036)$

deficiency in Danish children ${ }^{(7)}$. Tunisia, although not a tropical country, has a sunny climate and has also been reported to have a high prevalence of vitamin D deficiency in children and teenagers $(84.9 \%)^{(18)}$. In the Brazilian population, it is observed that younger age, outdoor physical activities, oral supplementation of vitamin $\mathrm{D}$, and living in coastal cities and at lower latitudes are related to better nutritional status of vitamin $\mathrm{D}^{(2)}$.

We found a higher prevalence of inadequate vitamin D $(<75 \mathrm{nmol} / \mathrm{l})$ in black- and brown-skinned children. In general, this has been attributed to the competition of melanin for UVB radiation, which is responsible for the photochemical fragmentation of the vitamin $\mathrm{D}$ precursor synthesized in the skin. However, it has been proposed that, despite the lowest total serum vitamin D concentrations, the black-skinned population has similar concentrations of bioavailable $25(\mathrm{OH}) \mathrm{D}$, due to the lower concentrations of vitamin D-binding protein ${ }^{(38)}$. No child reached the Estimated Average Requirement for vitamin D and this can be due to lower average consumption of vitamin D food sources by Brazilians. Low intake of this vitamin among Brazilian and foreign children was also observed in other studies ${ }^{(39-41)}$. Additionally, there was no association between intake and serum level of vitamin D, 
because it is estimated that $5-10 \%$ of bioavailable vitamin $\mathrm{D}$ is derived from food intake, the largest proportion being acquired by cutaneous synthesis ${ }^{(42)}$. This is consistent with data from other studies ${ }^{(5,9)}$ and strengthens the fact that sunlight exposure is the main source of vitamin D.

Previous studies in the paediatric population also found no association with total cholesterol, LDL cholesterol ${ }^{(43,44)}$, HDL cholesterol ${ }^{(9,36)}$ and blood pressure ${ }^{(45)}$. However, there are reports of an inverse association between vitamin $\mathrm{D}$ and TAG levels after adjustment for $\mathrm{BMI}^{(9,36,43)}$. In a study with Danish children, Petersen et al. ${ }^{(9)}$ performed the adjustment for FMI in addition to the adjustment for BMI, and the inverse association between concentration of vitamin D and TAG remained. Yet, our study showed that the inverse relationship between vitamin D and hypertriacylglycerolaemia is indeed confused by adiposity, particularly central adiposity. The loss of association between vitamin D and TAG was observed after adjustment for gynoid fat, waist-to-height ratio (central adiposity) and also FMI (general adiposity). However, the association with FMI was probably prompted by the impact of central adiposity.

BMI, as a measure of adiposity, is often used to control confounding effects of obesity on the relationship of nutrients with diseases ${ }^{(12,46)}$. Nevertheless, more accurate measures of adiposity such as assessment by dual-energy X-ray absorptiometry, computed tomography or MRI show that there is a direct relationship between body fat distribution and concentrations of $25(\mathrm{OH}) \mathrm{D}$, and central obesity as being a strong predictor of vitamin $\mathrm{D}$ serum concentration $^{(47)}$.

In the present study, the prevalence of insulin resistance was lower in children with adequate concentrations of $25(\mathrm{OH}) \mathrm{D}(\geq 75 \mathrm{nmol} / \mathrm{l})$. Studies have shown that hypovitaminosis D predisposes individuals to increased insulin resistance risk through mechanisms in pancreatic $\beta$-cells that can affect the insulin response to glucose stimulation $^{(48,49)}$

Besides changing the synthesis and secretion of insulin, vitamin D deficiency may play an important role in the prevention and treatment of diabetes by acting to reduce insulin resistance also via its immunomodulatory and antiinflammatory action ${ }^{(50)}$. Epidemiological studies have shown that children deficient in 25(OH)D had higher risk of developing diabetes, and that its supplementation may reduce this risk as well as having beneficial effects on the control of some complications caused by childhood obesity $^{(16,51)}$. The association between vitamin D and insulin resistance was independent of adiposity, indicating potential independent mechanisms of extra-bone action by vitamin $\mathrm{D}$. The relationship between overweight, insulin resistance and vitamin $\mathrm{D}$ can be explained by the release of NEFA from adipose tissue, which can induce the resistance to insulin, while vitamin D improves the NEFAinduced insulin resistance by neutralizing these fatty acids $^{(52)}$.
In this sense, the serum $25(\mathrm{OH}) \mathrm{D}$ concentrations categorized were independently associated with cardiometabolic risk markers, which reinforces the possibility that the serum vitamin D concentration may not be linearly associated with these changes, but may have an effect from a threshold. Randomized clinical trials with long follow-up periods are necessary to establish the causal relationship, as well as proposed cut-off points of serum vitamin D concentration for protection against cardiometabolic changes.

It is important to note that there was an inverse association between the prevalence of deficiency/insufficiency of vitamin $\mathrm{D}$ and the number of cardiometabolic risk factors in children in the present study. There is evidence that deficiency of $25(\mathrm{OH}) \mathrm{D}$ is associated with the metabolic syndrome, even in children and adolescents ${ }^{(11,16)}$. Although the specific mechanism of how vitamin D may protect individuals from cardiometabolic changes is not well understood, its function as a hormone has been increasingly recognized ${ }^{(53)}$. Mechanisms such as the regulation of renin-angiotensin system activity in pancreatic $\beta$-cells and suppression of inflammation have been suggested $^{(49,50,54)}$.

The American and Brazilian Societies of Endocrinology do not recommend the assessment of serum concentration of $25(\mathrm{OH}) \mathrm{D}$ for the general population due to the measurement cost. However, laboratory investigation is recommended in subjects at risk for hypovitaminosis D, including those who are obese ${ }^{(2,22)}$.

Recently, in Brazil, the Brazilian Society of Pediatrics published recommendations for vitamin D supplementation only for children under 2 years of age, including exclusive breast-feeding infants. It is important to encourage the adoption of healthy eating and lifestyle habits for children and teenagers, such as intake of food sources of vitamin $\mathrm{D}$ and outdoor physical activities associated with sun exposure ${ }^{(55)}$.

It is noteworthy that the present study was conducted with homogeneous sample regarding physiological characteristics, consisting of prepubescent children. Moreover, it is one of the few studies in developing countries that has assessed the serum concentration of vitamin $\mathrm{D}$ and its association with cardiometabolic risk factors in childhood; the first population-based study with prepubertal Brazilian children. Additionally, all confounding variables cited in the literature were used for adjustments in the statistical analysis of the study.

\section{Conclusion}

In conclusion, the results of the current investigation show that insufficiency/deficiency occurred in more than half of children and none of them reached the recommended intake of vitamin D. It is important to highlight that adequate serum concentration of vitamin D was inversely 
associated with the prevalence of insulin resistance, regardless of body fat location. The current lifestyle of children, with low intake of vitamin D and few outdoor activities, may explain the high prevalence of insufficiency/deficiency of $25(\mathrm{OH}) \mathrm{D}$ even in a tropical climate country like Brazil. Considering the importance of preventing chronic diseases beginning in childhood, strategies for adopting healthy habits to improve vitamin $\mathrm{D}$ nutritional status in this age group can be really relevant in order to avoid the repercussions of long-term cardiometabolic alterations.

\section{Acknowledgements}

Acknowledgments: The authors are grateful to the National Council for Scientific and Technological Development (CNPq) for financial support (process number 478910/ 2013-4); BIOCLIN ${ }^{\circledR}$ for providing material for biochemical analysis; and the Coordination for the Improvement of Higher Education Personnel (CAPES) for the granting of a master's scholarship. Financial support: This work was supported by the CNPq (grant number 478910/2013-4). The funders had no role in the design, analysis or writing of this article. Conflict of interest: The authors declare no conflict of interest. Authorship: L.C.M. conceived and designed this work and the analysis of the data, conducted the literature search, as well as wrote the manuscript. N.P.R. assisted with data collection, and revised and approved the final manuscript as submitted. M.S.F. assisted with data collection, and revised and approved the final manuscript as submitted. F.M.A. assisted with data collection, and revised and approved the final manuscript as submitted. A.P.P.C assisted with data collection, and revised and approved the final manuscript as submitted. M.C.P. supervised data analysis, assisted in the interpretation of results and approved the final manuscript as submitted. M.C.G.P. assisted in the interpretation of results and approved the final manuscript as submitted. J.F.N designed the study including the data collection, coordinated and supervised and approved the final manuscript as submitted. Ethics of buman subject participation: This study was conducted according to the guidelines defined in the Declaration of Helsinki and all procedures involving human subjects were approved by the Ethics Committee on Human Research of the Federal University of Viçosa (opinion number 663171/ 2014) and also presented to the Municipal Department of Education, the Regional Superintendent of Education and principals of schools. Informed consent was signed by parents.

\section{References}

1. Wacker M \& Holick MF (2013) Sunlight and vitamin D: a global perspective for health. Dermatoendocrinology $\mathbf{5}$, 51-108.
2. Maeda SS, Borba VZC, Camargo MBR et al. (2014) Recommendations of the Brazilian Society of Endocrinology and Metabolism for the diagnosis and treatment of vitamin D deficiency. Arq Bras Endocrinol Metab 58, 411-433.

3. Holick MF (2004) Sunlight and vitamin D for bone health and prevention of autoimmune diseases, cancers, and cardiovascular disease. Am J Clin Nutr 80, 6 Suppl., S1678-S1688.

4. Holick MF (2007) Vitamin D deficiency. N Engl J Med 357, 266-281.

5. Absoud M, Cummins C, Lim MJ et al. (2011) Prevalence and predictors of vitamin D insufficiency in children: a Great Britain population based study. PLOS ONE 6, e22179.

6. Misra M, Pacaud D, Petryk A et al. (2008) Vitamin D deficiency in children and its management: review of current knowledge and recommendations. Pediatrics 122, 398-417.

7. Guasch A, Bulló M, Rabassa A et al. (2012) Plasma vitamin $\mathrm{D}$ and parathormone are associated with obesity and atherogenic dyslipidemia: a cross-sectional study. Cardiovasc Diabetol 11, 149-159.

8. Dolinsky DH, Armstrong S, Mangarelli C et al. (2013) The association between vitamin $\mathrm{D}$ and cardiometabolic risk factors in children: a systematic review. Clin Pediatr 52, 210-223.

9. Petersen RA, Damsgaard CT, Dalskov SM et al. (2016) Vitamin D status and its determinants during autumn in children at northern latitudes: a cross-sectional analysis from the optimal well-being, development and health for Danish children through a healthy New Nordic Diet (OPUS) School Meal Study. Br J Nutr 115, 239-250.

10. Balagopal P, Ferranti SD, Cook S et al. (2011) Nontraditional risk factors and biomarkers for cardiovascular disease: mechanistic, research, and clinical considerations for youth: a scientific statement from the American Heart Association. Circulation 123, 2749-2769.

11. Ganji V, Zhang X, Shaikh N et al. (2011) Serum 25hydroxyvitamin $\mathrm{D}$ concentrations are associated with prevalence of metabolic syndrome and various cardiometabolic risk factors in US children and adolescents based on assayadjusted serum 25-hydroxyvitamin D data from NHANES 2001-2006. Am J Clin Nut 94, 225-233.

12. Alemzadeh R, Kichler J, Babar G et al. (2008) Hypovitaminosis D in obese children and adolescents: relationship with adiposity, insulin sensitivity, ethnicity, and season. Metabolism 57, 183-191.

13. Khan H, Kunutsor S, Franco O et al. (2013) Vitamin D, type 2 diabetes and other metabolic outcomes: a systematic review and meta-analysis of prospective studies. Proc Nutr Soc 72, 89-97.

14. Kayaniyil S, Harris S, Retnakaran R et al. (2014) Prospective association of $25(\mathrm{OH}) \mathrm{D}$ with metabolic syndrome. Clin Endocrinol 80, 502-507.

15. Mousa A, Naderpoor N, de Courten MP et al. (2016) 25-Hydroxyvitamin $\mathrm{D}$ is associated with adiposity and cardiometabolic risk factors in a predominantly vitamin Ddeficient and overweight/obese but otherwise healthy cohort. J Steroid Biochem Mol Biol (Epublication ahead of print version).

16. Kelishadi R, Salek S, Salek M et al. (2014) Effects of vitamin D supplementation on insulin resistance and cardiometabolic risk factors in children with metabolic syndrome: a triple-masked controlled trial. J Pediatr (Rio J) 90, 28-34.

17. Petersen RA, Dalskov SM, Sørensen LB et al. (2015) Vitamin D status is associated with cardiometabolic markers in 8-11year-old children, independently of body fat and physical activity. Br J Nutr 114, 1647-1655.

18. Bezrati I, Ben Fradj MK, Ouerghi N et al. (2016) Vitamin D inadequacy is widespread in Tunisian active boys and is related to diet but not to adiposity or insulin resistance. Libyan J Med 22, 31258. 
19. Nadeau KJ, Maahs DM, Daniels SR et al. (2011) Childhood obesity and cardiovascular disease: links and prevention strategies. Nat Rev Cardiol 8, 513-525.

20. Brazilian Institute of Geography and Statistics (2011) Social indicators. An analysis of the results of the 2010 Population Census universe. Studies \& Research: Demographic and socioeconomic information 2011. http://www.ibge.gov.br/home/ estatistica/populacao/censo2010/default.shtm (accessed November 2016).

21. Heaney RP (2013) What is vitamin D insufficiency? And does it matter? Calcif Tissue Int 92, 177-183.

22. Norman AW, Bouillon R, Whiting SJ et al. (2007) 13th Workshop consensus for vitamin D nutritional guidelines. $J$ Steroid Biochem Mol Biol 103, 204-205.

23. Holick MF, Binkley NC, Bischoff-Ferrari HA et al. (2011) Evaluation, treatment, and prevention of vitamin D deficiency: an Endocrine Society clinical practice guideline. J Clin Endocrinol Metab 96, 1911-1930.

24. World Health Organization, Onis M, Onyango AW et al. (2007) Development of a WHO growth reference for school-aged children and adolescents. Bull World Health Organ 85, 660-667.

25. Barbosa-Filho VC, Lopes AS, Fagundes RR et al. (2014) Anthropometric indexes in school in a city in southern Brazil: descriptive analysis using the LMS method. Rev Paul Pediatr 32, 333-341.

26. Lohman TG (1992) Assessing fat distribution. In Advances in Body Composition Assessment: Current Issues in Exercise Science, pp. 57-63. Champaign, IL: Human Kinetics.

27. Brazilian Society of Cardiology (2005) I Atherosclerosis Prevention Guideline on Childhood and Adolescence. Arq Bras Cardiol 85, 6 Suppl., S3-S36.

28. Tresaco B, Bueno G, Pineda I et al. (2005) Homeostatic model assessment (HOMA) index cut-off values to identify the metabolic syndrome in children. J Physiol Biochem 61, 381-388.

29. Brazilian Society of Cardiology (2010) VI Brazilian guidelines of hypertension. Arq Bras Cardiol 95, 1-5.

30. Institute of Medicine (2011) Dietary Reference Intakes for Calcium and Vitamin. D. Washington, DC: National Academies Press.

31. Willett W \& Stampfer M (1998) Implications of total energy intake for epidemiologic analyses. In Nutritional Epidemiology, pp. 273-301 [W Willett, editor]. New York: Oxford University Press.

32. Santos BR, Mascarenhas LP, Satler F et al. (2012) Vitamin D deficiency in girls from South Brazil: a cross-sectional study on prevalence and association with vitamin D receptor gene variants. BMC Pediatr 12, 62.

33. Centers for Disease Control and Prevention (2007) Reducing children's TV time to reduce the risk of childhood overweight: the children's media use study. Report highlights. http://www.cdc.gov/nccdphp/dnpa/obesity/pdf/TV_Time_ Highlights (accessed October 2016).

34. Santos A, Andaki ACR, Amorim PRS et al. (2013) Fatores associados ao comportamento sedentário em escolares de 9-12 anos de idade. Motriz 19, 1 Suppl., S25-S34.

35. Lourenço BH, Qi L, Willett WC et al. (2014) FTO genotype, vitamin D status, and weight gain during childhood. Diabetes $\mathbf{6 3}, 808-814$.

36. Delvin EE, Lambert M, Levy E et al. (2010) Vitamin D status is modestly associated with glycemia and indicators of lipid metabolism in French-Canadian children and adolescents. J Nutr 140, 987-991.

37. Beuzit C, L'Hour MC, Roudaut S et al. (2015) Prévalence du déficit en vitamine $D$ chez les enfants ages de 5 a 10 ans en Bretagne Occidentale. Arch Pediatr 22, 1112-1118.
38. Powe CE, Evans MK, Wenger J et al. (2013) Vitamin D-binding protein and vitamin D status of Black Americans and White Americans. N Engl J Med 369, 1991-2000.

39. Díez-Gañán L, Labaca IG, Domínguez CML et al. (2007) Ingesta de alimentos, energía y nutrientes en la población de 5 a 12 años de la comunidad de Madrid: resultados de la encuesta de nutrición infantil 2001-2002. Rev Esp Salud Publica 81, 543-558.

40. Bueno AL \& Czepielewski MA (2010) The 24-hour recall as a tool in assessing the food intake of calcium, phosphorus and vitamin $\mathrm{D}$ in children and adolescents with short stature. Rev Nutr 23, 65-73.

41. Anta RMO, González-Rodríguez LG, Ortega AIJ et al. (2012) Ingesta insuficiente de vitamina $\mathrm{D}$ en población infantil española; condicionantes del problema y bases para su mejora. Nutr Hosp 27, 1437-1443.

42. Holick MF (2005) The vitamin D epidemic and its health consequences. J Nutr 135, issue 11, 2739S-2748S.

43. Rodriguez-Rodriguez E, Ortega RM, Gonzalez-Rodriguez LG et al. (2011) Vitamin D deficiency is an independent predictor of elevated triglycerides in Spanish school children. Eur J Nutr 50, 373-378.

44. Williams DM, Fraser A, Sayers A et al. (2012) Associations of 25-hydroxyvitamin $\mathrm{D}_{2}$ and $\mathrm{D}_{3}$ with cardiovascular risk factors in childhood: cross-sectional findings from the Avon Longitudinal Study of Parents and Children. J Clin Endocrinol Metab 97, 1563-1571.

45. Peters BSE, Roque JP, Fisberg M et al. (2009) Serum metabolites of vitamin D does not relate to blood pressure in adolescents. Arq Bras Endocrinol Metabol 53, 416-424.

46. Saneei P, Salehi-Abargouei A \& Esmaillzadeh A (2013) Serum 25-hydroxy vitamin D levels in relation to body mass index: a systematic review and meta-analysis. Obes Rev 14, 393-404.

47. Hao Y, Ma X, Shen Y et al. (2014) Associations of serum 25-hydroxyvitamin $\mathrm{D}_{3}$ levels with visceral adipose tissue in Chinese men with normal glucose tolerance. PLoS One 9, e86773.

48. Zeitz U, Weber K, Soegiarto Dw et al. (2003) Impaired insulin secretory capacity in mice lacking a functional vitamin D receptor. FASEB J 17, 509-511.

49. Snijder MB, Van Dam RM, Visser M et al. (2005) Adiposity in relation to vitamin D status and parathyroid hormone levels: a population-based study in older men and women. J Clin Endocrinol Metabol 90, 4119-4123.

50. Marcotorchino J, Gouranton E, Romier B et al. (2012) Vitamin D reduces the inflammatory response and restores glucose uptake in adipocytes. Mol Nutr Food Res 56, 1771-1782.

51. Zipitis CS \& Akobeng AK (2008) Vitamin D supplementation in early childhood and risk of type 1 diabetes: a systematic review and meta-analysis. Arch Dis Child 93, 512-517.

52. Zhou QG, Hou FF, Guo ZJ et al. (2008) 1,25-Dihydroxyvitamin $D$ improved the free fatty-acid-induced insulin resistance in cultured C2C12 cells. Diabetes Metab Res Rev 24, 459-464.

53. Bouillon R, Carmeliet G, Verlinden L et al. (2008) Vitamin D and human health: lessons from vitamin $\mathrm{D}$ receptor null mice. Endocr Rev 29, 726-776.

54. Bland R, Markivic F, Hilss CE et al. (2004) Expression of 25-hydroxivitamin $\mathrm{D}_{3}-\alpha$-hydroxylase in pancreatic islets. J Steroid Biochem Mol Biol 90, 121-125.

55. Brazilian Society of Pediatrics, Department of Nutrition (2014) Vitamin D Deficiency in Children and Adolescents. http://www.sbp.com.br/src/uploads/2015/02/vitamina_d_ dcnutrologia2014-2.pdf (accessed December 2015). 